\title{
AbobotulinumtoxinA in the management of cervical dystonia in the United Kingdom: a budget impact analysis
}

This article was published in the following Dove Press journal:

ClinicoEconomics and Outcomes Research

9 September 2015

Number of times this article has been viewed

\author{
Seye Abogunrin' \\ Sarah Brand ${ }^{2}$ \\ Kamal Desai ${ }^{3}$ \\ Jerome Dinet ${ }^{4}$ \\ Sylvie Gabriel ${ }^{5}$ \\ Timothy Harrower 6 \\ 'Meta Research, Evidera, London, UK; \\ ${ }^{2}$ Health Economics, Evidera, Bethesda, \\ MD, USA; ${ }^{3}$ Health Economics, Evidera, \\ London, UK; ${ }^{4}$ Health Economics \\ and Outcomes Research (Global), \\ ${ }^{5}$ Global Market Access and Pricing, \\ Ipsen Pharma, Boulogne-Billancourt, \\ France; ${ }^{6}$ Royal Devon and Exeter NHS \\ Foundation Trust, Exeter, UK
}

Correspondence: Seye Abogunrin Meta Research, Evidera, Metro Building, 6th Floor, No I Butterwick, London W6 8DL, UK

Tel +442085765049

Fax +44208575195

Email seye.abogunrin@evidera.com
Background: Cervical dystonia (CD) can be effectively managed by a combination of botulinum neurotoxin A (BoNT-A) and conventional therapy (skeletal muscle relaxants and rehabilitative therapy), but the costs of different interventions in the UK vary.

Methods: A budget impact model was developed from the UK payer perspective with a 5-year time horizon to evaluate the effects of changing market shares of abobotulinumtoxinA, onabotulinumtoxinA, and incobotulinumtoxinA, and best supportive care from the UK payer perspective. Epidemiological and resource use data were retrieved from the published literature and clinical expert opinion. Deterministic sensitivity analyses were performed to determine the parameters most influential on the budgetary findings under base case assumptions.

Results: Under base case assumptions, an increased uptake of abobotulinumtoxinA showed an accumulated savings of $£ 2,250,992$ by year 5 . Treatment per patient per year with onabotulinumtoxinA and incobotulinumtoxinA costs more when compared to treatment with abobotulinumtoxinA. One-way sensitivity analyses showed that the prevalence of $\mathrm{CD}$, dose per injection of each of the BoNT-As, and time to reinjection of incobotulinumtoxinA and abobotulinumtoxinA influenced the base case findings most.

Conclusion: There is potential for cost savings associated with the greater use of abobotulinumtoxinA rather than other BoNT-A treatments, permitting more patients to benefit more from effective BoNT-A treatment with a fixed budget.

Keywords: cervical dystonia, torticollis, botulinum toxin A, budget impact analysis

\section{Introduction}

Dystonias are severe disorders causing involuntary contraction of the skeletal muscles, abnormal posture, and severe pain or discomfort. The most commonly reported type of focal, segmental, multifocal, generalized, or ipsilateral dystonia is cervical dystonia (CD), which particularly affects the muscles controlling the neck and shoulders in middle-aged patients. ${ }^{1-3} \mathrm{CD}$ may be idiopathic or acquired. Idiopathic $\mathrm{CD}$ is often dependent on a genetic predisposition, while acquired CD results from trauma to either the central or peripheral nerves controlling the neck muscles. ${ }^{4}$ There appears to be a dearth of evidence on the epidemiology of CD in the UK. The prevalence of CD in Europe seems to be higher compared to the rest of the world, with numbers ranging between 8 and 233 cases per 1,000,000 population..$^{5,6}$ In the UK alone, the prevalence of $\mathrm{CD}$ has been reported to be 61 cases per 1,000,000. ${ }^{6}$ Data on the economic burden of $\mathrm{CD}$ in the UK is relatively scarce, but 6-month costs have been estimated in the USA to range from $\$ 1,255$ to as high as $\$ 63,320 .{ }^{1}$ Due to the complexity associated with the management of $\mathrm{CD}$, current guidelines include a mixture of medical, 
surgical, and physical therapy options, such as treatment with botulinum toxin, deep brain stimulation, and selective peripheral denervation. ${ }^{2,7,8}$

Botulinum neurotoxin A (BoNT-A) is effective ${ }^{9-11}$ in managing CDs, especially when combined with conventional therapy, which consists of skeletal muscle relaxants and rehabilitative therapy. Thus, the use of BoNT-As can alleviate the burden of care associated with managing CD on a day-to-day basis, ${ }^{12-14}$ and potentially improve both patients' and their caregivers' quality of life. In addition, BoNT-As usage in patients with CD have been shown to improve productivityrelated gains resulting in decreased absenteeism and sickness leave. ${ }^{15,16}$ There are three BoNT-As used in the treatment of CD in the UK abobotulinumtoxinA (Dysport ${ }^{\circledR}$; Ipsen Biopharm SAS, Boulogne-Billancourt, France), onabotulinumtoxin A (Botox ${ }^{\circledR}$; Allergan, Inc., Irvine, CA, USA), and incobotulinumtoxinA (Xeomin ${ }^{\circledR}$ : Merz Pharma $\mathrm{GmbH}$ and Co KGaA, Frankfurt am Main, Germany), and there is evidence to suggest that there are differences in the characteristics of these BoNT-As, including time to first improvement, duration of symptomatic relief, and maximum benefit derived by patients. ${ }^{17}$ However, without comparative head-to-head trials of BoNT-As, it is widely assumed that all are equally effective, although costs may vary. Given these variations in costs, and the aforementioned benefits associated with the different BoNT-As, we investigated the budget impact of treating patients with $\mathrm{CD}$ in the UK with BoNT-As, taking into account assumptions on evolution of market shares.

\section{Methods}

\section{Overview}

We explored the possibility of budgetary changes that could be associated with the use of abobotulinumtoxinA, onabotulinumtoxinA, or incobotulinumtoxin A as a major component of treatment of CD in the UK by developing a budget impact model in Excel (2007). Our model evaluated two scenarios: the status quo (the current mix of available competing BoNT-A treatments according to their prevailing market shares) and a new market share scenario, which assumed a hypothetical increased uptake of abobotulinumtoxinA relative to its competitors. We defined the budget impact of increasing the market share of abobotulinumtoxinA as the difference in costs of the new market share and status quo scenarios.

The analysis was conducted from the UK National Health Service and Personal Social Services perspective over a 5-year time horizon. The model required epidemiological, resource use, unit costs, and market share data. These data were derived from several sources, which included published literature, the British National Formulary (BNF), ${ }^{18}$ Personal Social Services, ${ }^{19}$ and interviews with UK clinicians. In both scenarios, we examined abobotulinumtoxinA, onabotulinumtoxin $\mathrm{A}$, incobotulinumtoxin $\mathrm{A}$, and best supportive care without BoNT-A treatment. Best supportive care in our budget impact assessment comprised only the use of select pharmacotherapy (analgesics and skeletal muscle relaxants) and rehabilitative therapy. Generally, in situations where we were unable to identify or retrieve data on the UK, we incorporated Europe-level or global-level data.

The budget impact model accounted first for the number of patients eligible for the different BoNT-A treatments each year using the estimated prevalence of CD. BoNT-A-eligible patients were distributed to receive each type of treatment based on the market shares in the status quo and new market share scenarios. Annual costs of each intervention were calculated using the unit costs and the frequency of the different resource use categories. The net budgetary impact of an increased market share was defined as the difference between the total costs for both scenarios. The model allows for the calculation of the following outcomes: number of patients receiving treatment by year; annual cost of interventions compared; annual costs of other medical services; and net budget impact.

\section{Patient population}

For the prevalence of $\mathrm{CD}$ in the UK, we used data from representative populations similar to the UK population. The prevalence of CD was estimated to range between $0.0057 \%$ and $0.037 \%$, translating to between $3,512^{6}$ and 23,037 (Ipsen Biopharm Ltd, unpublished data, 2012) patients, all of which we assumed were receiving care at any point in time. A European study by the Epidemiological Study of Dystonia in Europe (ESDE) Collaborative Group ${ }^{6}$ examined patients with $\mathrm{CD}$ from eight countries and reported the lowest prevalence figures, but note that these are underestimates. Based on a Finnish study by Erjanti et al, ${ }^{20}$ in which the authors conducted a more active detection of cases, we inferred the prevalence of $\mathrm{CD}$ to be 13,324 . We considered this latter figure to be a more realistic estimate of the prevalence of CD and, therefore, adopted this figure for our base case prevalence assumption; 23,037 patients were used as the upper limit of the range (Ipsen Biopharm Ltd, unpublished data, October 2012). Of the estimated 13,324 patients receiving any treatment for $\mathrm{CD}$, we assumed that $80 \%$ of these would receive BoNT-A treatment at any point in time, due to the delay in onset to correct diagnosis or due to other reasons 
that not all patients will get BoNT-A (Ipsen Biopharm Ltd, unpublished data, 2012). The actual prevalence may be higher given that the Dystonia Society reports that CD is a very under-recognized condition, with patients reporting that it can take 3 or 4 years before a diagnosis is made by referral to a neurologist. ${ }^{21}$ Table 1 shows a summary of the prevalence estimates.

\section{Market shares and BoNT-A dosing}

Status quo market share data indicate that $69 \%, 15.5 \%$, and $15.5 \%$ of patients with CD currently receive abobotulinumtoxinA, onabotulinumtoxinA, and incobotulinumtoxinA, respectively (Ipsen Biopharm Ltd, unpublished data, 2012), while new market share hypothesized a 3\% annual increase each year to year 5 for abobotulinumtoxinA, reaching $81 \%$ for abobotulinumtoxinA with a commensurate decline in market share for other BoNT-As. Table 2 gives more details on the status quo and new market share scenarios. Our base case analysis included dosages for all three BoNT-As derived from the summary of product characteristics (SPC). ${ }^{22-24}$ In addition, we assumed that BoNT-A units are not interchangeable, and that there was no dose ratio. Patients treated with abobotulinumtoxinA were assumed to receive 500 units of the injection per dose, ${ }^{22}$ while onabotulinumtoxinA and incobotulinumtoxinA were assumed to have been administered as 200 units each. ${ }^{23,24}$ A mean reinjection interval of 12 weeks for abobotulinumtoxinA and onabotulinumtoxinA was inferred from the SPC, while time to reinjection of incobotulinumtoxinA was 10 weeks.

\section{Costs}

We included direct costs only in this analysis, as the budget impact assessment was conducted from a third-party payer

Table I Prevalence of CD

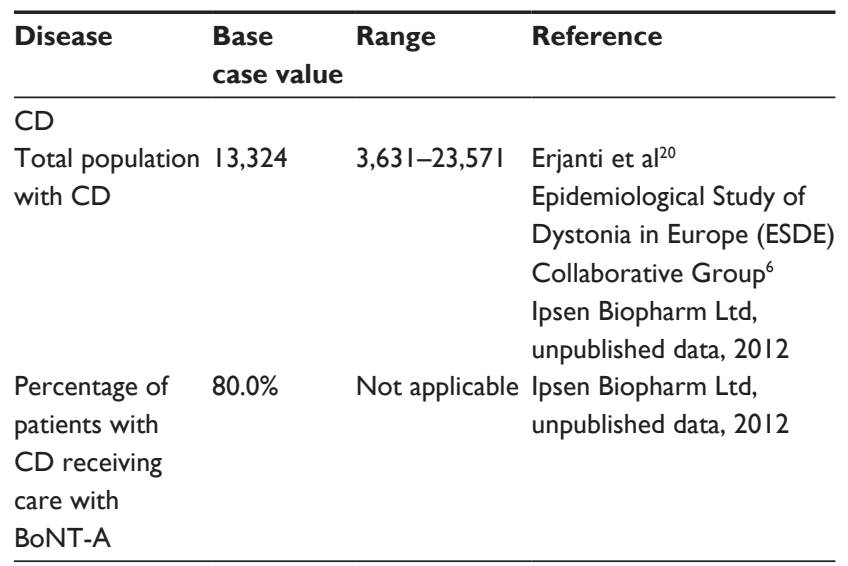

Abbreviations: $C D$, cervical dystonia; BoNT-A, botulinum neurotoxin A.

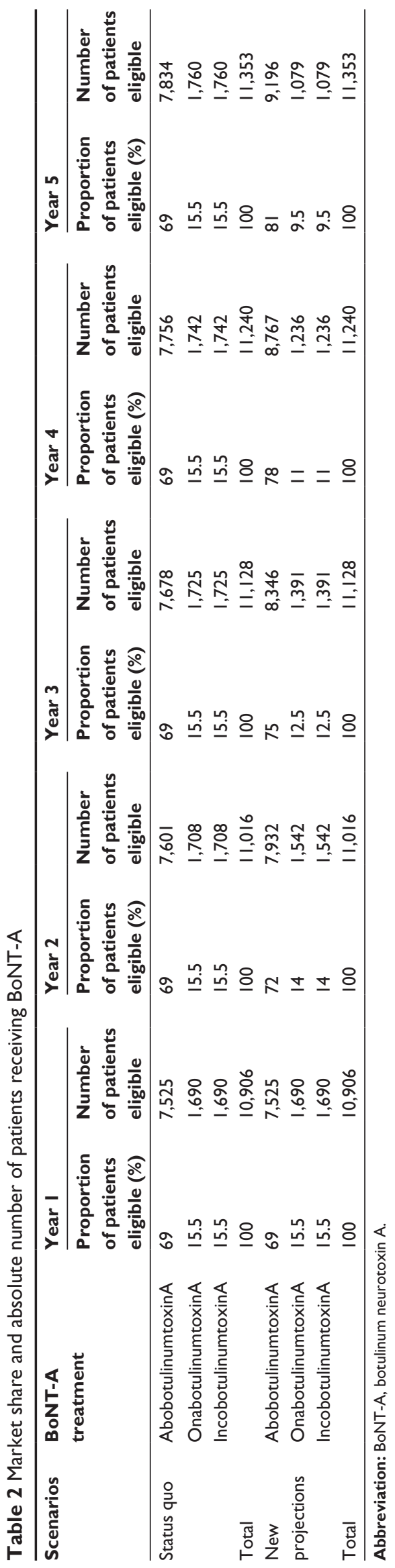


perspective. We identified unit costs from the BNF, Personal Social Services Research Unit, and clinical expert opinion, where possible. The various costs included in the analysis comprised unit costs of BoNT-A vials, costs related to concomitant medications, and costs of other resource use related to laboratory tests and procedures, as well as health care professional contact. Since BoNT-A injection vials are manufactured in different sizes, specialists administering the injections were assumed to use the smallest possible vial combinations. In addition, we assumed that there was no vial sharing among patients. Table 3 shows the details of the unit costs and dosages of BoNT-A injections included in the analysis. Cost data used for our analysis were retrieved from the BNF. ${ }^{18}$ The dosages of the BoNT-A injections were, however, based on the suggested clinical doses reported in the SPCs, and the variation around their estimates were either based on the corresponding SPC for each BoNT-A or expert clinical opinion.

Resource use for BoNT-A treatment arms were essentially the same, except for the costs of the BoNT-A. Cost differences arise between treatment with BoNT-A and treatment without BoNT-A - the proportional use of anticholinergics, dopamine antagonists, beta-blockers, antiepileptics, muscle relaxants, and the need for selective peripheral denervation and laboratory tests. In general, data on proportional resource use by patients was unavailable in the published literature. We therefore used data based on clinical expert opinion. On the other hand, the dosage data was derived from the BNF. ${ }^{18}$ Further details are provided in Table 4. It should be noted that as the market share evolution involved changes only to BoNT-A, and not to best supportive care without BoNT-A, the budget impact will not depend on best supportive care costs. However, cost comparisons between patients receiving treatment with and without BoNT-A were possible.

\section{Analysis}

Base case analyses were conducted using the epidemiological, market share, cost, and resource use figures given earlier. One-way sensitivity analyses were conducted to determine which parameters were most sensitive to change in the model. Model parameters were varied between high and low values based on the ranges identified from the literature, when data were available. For data where the ranges could not be specified, a predefined $\pm 20 \%$ range was used to test the parameters. The results are presented as a tornado diagram. We also considered an alternative "real-world" scenario analysis where BoNT-A doses and reinjection intervals were based on a clinical expert's input rather than SPC figures to ascertain how net budgetary differences could depend on these alternative assumptions. Details of the BoNT-A doses

Table 3 BoNT-A medication treatment cost and dosage

\begin{tabular}{|c|c|c|c|c|}
\hline \multirow[t]{2}{*}{ BoNT-A } & \multirow[t]{2}{*}{ Base case value } & \multicolumn{2}{|l|}{ Range } & \multirow[t]{2}{*}{ Source } \\
\hline & & Minimum & Maximum & \\
\hline \multicolumn{5}{|l|}{ AbobotulinumtoxinA } \\
\hline $\begin{array}{l}\text { Vial cost of abobotulinumtoxinA } \\
\text { (300 units) }\end{array}$ & $£ 92.40$ & $£ 73.92$ & $£ \mid I 0.88$ & $\begin{array}{l}\text { British National Formulary; }{ }^{18} \text { range for costs were } \\
\text { assumed at } \pm 20 \%\end{array}$ \\
\hline $\begin{array}{l}\text { Vial cost of abobotulinumtoxinA } \\
\text { (500 units) }\end{array}$ & $£ \mid 54.00$ & $£ \mid 23.20$ & $£ \mid 84.80$ & $\begin{array}{l}\text { British National Formulary; }{ }^{18} \text { range for costs were } \\
\text { assumed at } \pm 20 \%\end{array}$ \\
\hline Dosage per injection of abobotulinumtoxinA & 500 units & 500 units & 1000 units & SPC;22 range informed by clinical expert opinion \\
\hline Reinjection interval for abobotulinumtoxinA & 12 weeks & 12 weeks & 12 weeks & SPC;22 range informed by clinical expert opinion \\
\hline \multicolumn{5}{|l|}{ OnabotulinumtoxinA } \\
\hline $\begin{array}{l}\text { Vial cost of onabotulinumtoxinA } \\
\text { (50 units) }\end{array}$ & $£ 77.50$ & $£ 62.00$ & $£ 93.00$ & $\begin{array}{l}\text { British National Formulary; }{ }^{18} \text { range for costs were } \\
\text { assumed at } \pm 20 \%\end{array}$ \\
\hline $\begin{array}{l}\text { Vial cost of onabotulinumtoxinA } \\
\text { (100 units) }\end{array}$ & $£ \mid 38.20$ & $£ \mid 10.56$ & $£ 165.84$ & $\begin{array}{l}\text { British National Formulary; }{ }^{18} \text { range for costs were } \\
\text { assumed at } \pm 20 \%\end{array}$ \\
\hline $\begin{array}{l}\text { Vial cost of onabotulinumtoxinA } \\
\text { ( } 200 \text { units) }\end{array}$ & $£ 276.40$ & $£ 221.12$ & $£ 331.68$ & $\begin{array}{l}\text { British National Formulary; }{ }^{18} \text { range for costs were } \\
\text { assumed at } \pm 20 \%\end{array}$ \\
\hline Dosage per injection of onabotulinumtoxinA & 200 units & 200 units & 300 units & SPC; ${ }^{23}$ range informed by clinical expert opinion \\
\hline Reinjection interval for onabotulinumtoxinA & 12 weeks & 10 weeks & 12 weeks & SPC; $;^{23}$ range informed by clinical expert opinion \\
\hline \multicolumn{5}{|l|}{ IncobotulinumtoxinA } \\
\hline $\begin{array}{l}\text { Vial cost of incobotulinumtoxinA } \\
\text { (50 units) }\end{array}$ & $£ 72.00$ & $£ 57.60$ & $£ 86.40$ & $\begin{array}{l}\text { British National Formulary; }{ }^{18} \text { range for costs were } \\
\text { assumed at } \pm 20 \%\end{array}$ \\
\hline $\begin{array}{l}\text { Vial cost of incobotulinumtoxinA } \\
\text { (100 units) }\end{array}$ & $£ 129.90$ & $£ 103.92$ & $£ \mid 55.88$ & $\begin{array}{l}\text { British National Formulary; }{ }^{18} \text { range for costs were } \\
\text { assumed at } \pm 20 \%\end{array}$ \\
\hline Dosage per injection of incobotulinumtoxinA & 200 units & 200 units & 300 units & SPC; ${ }^{24}$ range informed by clinical expert opinion \\
\hline Reinjection interval for incobotulinumtoxinA & 10 weeks & 10 weeks & 12 weeks & SPC; ${ }^{24}$ range informed by clinical expert opinion \\
\hline
\end{tabular}

Abbreviations: BoNT-A, botulinum neurotoxin A; SPC, summary of product characteristics. 
Table 4 Resource use for BoNT-A and best supportive care (without BoNT-A) arms in the base case

\begin{tabular}{|c|c|c|c|c|c|}
\hline Resource use item & $\begin{array}{l}\text { BoNT-A arm, } \\
\% \text { using }\end{array}$ & $\begin{array}{l}\text { BoNT-A arm, } \\
\text { amount }\end{array}$ & $\begin{array}{l}\text { BSC arm, } \\
\% \text { using }\end{array}$ & $\begin{array}{l}\text { BSC arm, } \\
\text { amount }\end{array}$ & Sources \\
\hline \multicolumn{6}{|l|}{ Concomitant medication } \\
\hline Anticholinergics & 0.6 & I mg daily dose & 5 & I mg daily dose & $\begin{array}{l}\text { UK clinical expert opinion; } \\
\text { British National Formulary }\end{array}$ \\
\hline Clonazepam & 26.5 & I mg daily dose & 26.5 & I mg daily dose & $\begin{array}{l}\text { UK clinical expert opinion; } \\
\text { British National Formulary }\end{array}$ \\
\hline Analgesics & 33.5 & I g daily dose & 33.5 & I g daily dose & $\begin{array}{l}\text { UK clinical expert opinion; } \\
\text { British National Formulary }{ }^{18}\end{array}$ \\
\hline Dopamine antagonist & 0 & NA & 5 & $2.5 \mathrm{mg}$ daily dose & $\begin{array}{l}\text { UK clinical expert opinion; } \\
\text { British National Formulary }\end{array}$ \\
\hline Beta-blockers & 0 & NA & 0.6 & 40 mg daily dose & $\begin{array}{l}\text { UK clinical expert opinion; } \\
\text { British National Formulary }\end{array}$ \\
\hline Baclofen & 0 & NA & 3.2 & $60 \mathrm{mg}$ daily dose & $\begin{array}{l}\text { UK clinical expert opinion; } \\
\text { British National Formulary }\end{array}$ \\
\hline Antiepileptics & 0 & NA & 5.8 & $600 \mathrm{mg}$ daily dose & $\begin{array}{l}\text { UK clinical expert opinion; } \\
\text { British National Formulary }\end{array}$ \\
\hline Other muscle relaxants & 0 & NA & 22.6 & $7.5 \mathrm{mg}$ daily dose & $\begin{array}{l}\text { UK clinical expert opinion; } \\
\text { British National Formulary }{ }^{18}\end{array}$ \\
\hline \multicolumn{6}{|l|}{ Health care professional } \\
\hline Neurologist visit (for injection) & 73.5 & 4.33 visits per year ${ }^{a}$ & 0 & NA & UK clinical expert opinion \\
\hline Neurophysiologist visit (for injection) & 26.5 & 4.3 visits per year $^{\mathrm{a}}$ & 0 & NA & UK clinical expert opinion \\
\hline Neurologist visit (excluding injections) & 0 & NA & 100 & 2 visits per year & UK clinical expert opinion \\
\hline GP visit & 100 & 2 visits per year & 100 & 2 visits per year & UK clinical expert opinion \\
\hline Hospitalization & 1.5 & I visit per year & 1.5 & I visit per year & UK clinical expert opinion \\
\hline \multicolumn{6}{|l|}{ Laboratory test } \\
\hline Blood test & 0 & 0 & 10 & 4 times per year & UK clinical expert opinion \\
\hline \multicolumn{6}{|l|}{ Procedures } \\
\hline EMG with needle & 5 & 4.33 times per year ${ }^{a}$ & 0 & NA & UK clinical expert opinion \\
\hline Deep brain stimulation & 0 & NA & 1 & I time per year & UK clinical expert opinion \\
\hline Selective peripheral denervation & 0 & NA & 1 & I time per year & UK clinical expert opinion \\
\hline
\end{tabular}

Note: ${ }^{\text {F}}$ requency of resource use is linked to reinjection interval.

Abbreviations: BoNT-A, botulinum neurotoxin A; BSC, best supportive care; NA, not available; GP, general practitioner; EMG, electromyography; UK, United Kingdom.

and reinjection intervals used in this real-world scenario are given in Table 5.

\section{Results}

Under base case assumptions, the total 5-year expected cost of treating patients with $\mathrm{CD}$ was $£ 101,996,037$, while under the

Table 5 BoNT-A medication dosage for "real-world" settings

\begin{tabular}{lll}
\hline BoNT-A & Mean & Source \\
\hline $\begin{array}{l}\text { AbobotulinumtoxinA } \\
\text { Dosage per injection of } \\
\text { abobotulinumtoxinA }\end{array}$ & 448 units & Hubble et al ${ }^{27}$ \\
$\begin{array}{l}\text { Reinjection interval for } \\
\text { abobotulinumtoxinA } \\
\text { OnabotulinumtoxinA }\end{array}$ & II weeks & Clinical expert opinion \\
$\begin{array}{l}\text { Dosage per injection of } \\
\text { onabotulinumtoxinA }\end{array}$ & 142 units & Marchetti et al ${ }^{28}$ \\
$\begin{array}{l}\text { Reinjection interval for } \\
\text { onabotulinumtoxinA } \\
\text { IncobotulinumtoxinA } \\
\text { Dosage per injection of } \\
\text { incobotulinumtoxinA }\end{array}$ & 11 weeks & Clinical expert opinion \\
$\begin{array}{l}\text { Reinjection interval for } \\
\text { incobotulinumtoxinA }\end{array}$ & 200 units & Misra et al ${ }^{29}$ \\
\hline
\end{tabular}

Abbreviation: BoNT-A, botulinum neurotoxin A. new market share scenario, it was $£ 99,745,045$, due mostly to BoNT-A drug costs and health care professional visits. An increased uptake of abobotulinumtoxinA resulted in a total of $£ 2,250,992$ accumulated savings at the end of year 5 . Total costs decreased by between $£ 220,611$ in year 2 and $£ 909,441$ in year 5 by increasing the market share of abobotulinumtoxinA gradually over the 5 -year period. The net budget impact is presented in Table 6 .

In the base case scenario, treatment per patient per year with onabotulinumtoxinA $(£ 2,011)$ and incobotulinumtoxinA $(£ 2,285)$ costs more compared to treatment with abobotulinumtoxinA (£1,480). Additionally, the annual costs associated with health care professional contact were lower for abobotulinumtoxinA and onabotulinumtoxinA ( $£ 718$ each) compared to incobotulinumtoxinA (£839). All other annual costs associated with concomitant medication use, laboratory procedures, other medical/social services resource use, and nonmedical resource use were similar for all three BoNT-As. Figure 1 provides further details of the costs associated with BoNT-A treatments.

On comparison of all four possible interventions (Figure 1), the major cost drivers common to all four were 
Table 6 Net 5-year budget impact of increasing abobotulinumtoxinA market share compared to status quo assumptions in the treatment of cervical dystonia in the UK

\begin{tabular}{|c|c|c|c|c|c|c|}
\hline & Year I (t) & Year $2(t)$ & Year $3(t)$ & Year $4(t)$ & Year $5(t)$ & Total $(\varepsilon)$ \\
\hline Budget under status quo assumptions & $|9,99|, 484$ & $20,193,298$ & $20,397,149$ & $20,603,059$ & $20,811,047$ & $101,996,037$ \\
\hline $\begin{array}{l}\text { Budget under new market share } \\
\text { assumptions }\end{array}$ & $|9,99|, 484$ & $19,972,687$ & $|9,95|, 473$ & $19,927,795$ & $19,90 \mid, 606$ & $99,745,045$ \\
\hline Net budget impact & 0 & $-220,6$ II & $-445,677$ & $-675,264$ & $-909,441$ & $-2,250,992$ \\
\hline
\end{tabular}

contact with health care professionals - best supportive care (£467) and use of concomitant medications (all BoNT-As £95 each; best supportive care $£ 114$ ) - while the medication costs associated with BoNT-A use was the main distinguishing factor between BoNT-A treatment.

One-way sensitivity analyses applied to the base case showed that the prevalence of CD; dose per injection of onabotulinumtoxinA, incobotulinumtoxin A, and abobotulinumtoxinA; and time to reinjection of incobotulinumtoxin $\mathrm{A}$ and abobotulinumtoxinA were the most influential parameters on net budget impact. Under the parameter ranges explored, abobotulinumtoxinA was always cost saving. Figure 2 is a tornado diagram showing the most important factors influencing the results of the base case analysis. (Table 7 provides definition for the abbreviations used).

\section{Discussion}

Our results suggest that the 3\% annual increased use of abobotulinumtoxinA in comparison with other BoNT-As has the potential to result in budgetary savings of $£ 2,250,992$ over a 5-year period in the UK, compared to the current market

Table 7 Variable description for tornado diagram

\begin{tabular}{ll}
\hline Variable & Variable description \\
\hline Time_Dysport & Time to reinjection of abobotulinumtoxinA \\
NumVisY_D_Neurlnj & $\begin{array}{l}\text { Number of visits per year - neurologist } \\
\text { (for injection) on abobotulinumtoxinA arm }\end{array}$ \\
Time_Botox & Time to reinjection of onabotulinumtoxinA \\
Dose_Dysport & Dosage per injection of abobotulinumtoxinA \\
Dose_Botox & Dosage per injection of onabotulinumtoxinA \\
Dose_Xeomin & Dosage per injection of incobotulinumtoxinA \\
CDPrev & Prevalence of cervical dystonia \\
VialC_XeominI00 & Vial cost of incobotulinumtoxinA (I00 units) \\
VialC_Dysport500 & Vial cost of abobotulinumtoxinA (500 units) \\
Time_Xeomin & Time to reinjection of incobotulinumtoxinA \\
VialC_Botox200 & Vial cost of onabotulinumtoxinA (200 units) \\
CDTrt & Percentage of cervical dystonia patients \\
NumVisY_D_Physio & who receive care \\
Number of visits per year - neurophysiologist & on abobotulinumtoxinA arm \\
PropUt_D_Neurlnj & Proportion utilizing neurologist (for injection) \\
UnitC_D_Neurlnj & on abobotulinumtoxinA arm \\
Unit cost - neurologist (for injection) on \\
abobotulinumtoxinA arm
\end{tabular}

share distribution of the use of BoNT-As. Second, the annual costs per patient of abobotulinumtoxinA use were much lower compared to onabotulinumtoxinA or incobotulinumtoxinA. However, best supportive care annual costs per patient were lower than for any of the BoNT-A treatments. This difference between best supportive care and BoNT-A treatments was understandable, as it was related to the costs of administering the BoNT-A injections. As the annual costs of treating patients with abobotulinumtoxinA compared to other BoNT-As are much less, it may be possible to treat more patients with CD within a particular budget. Lastly, switching more people to a cheaper, equally effective drug is more cost saving. It is important to note that there are no differences in the efficacy of the three BoNT-As we evaluated. A recent mixed treatment comparison found no significant differences in the efficacy profiles of abobotulinumtoxinA, incobotulinumtoxinA, and onabotulinumtoxin $\mathrm{A} .{ }^{25}$ Furthermore, a recent consensus statement by the European Federation of Neurological Societies concluded that there were no differences in the formulations of BoNT-As in relation to the treatment of CD. ${ }^{26}$ As a result, any savings accruable to the use of any of them can reasonably be assumed to be tied to the cost of administering each of these BoNT-As. The costs of administering each of these BoNT-As per patient mainly include the cost of the BoNT-A medication, as well as the costs associated with health care professional contact or visits. Our results, however, found

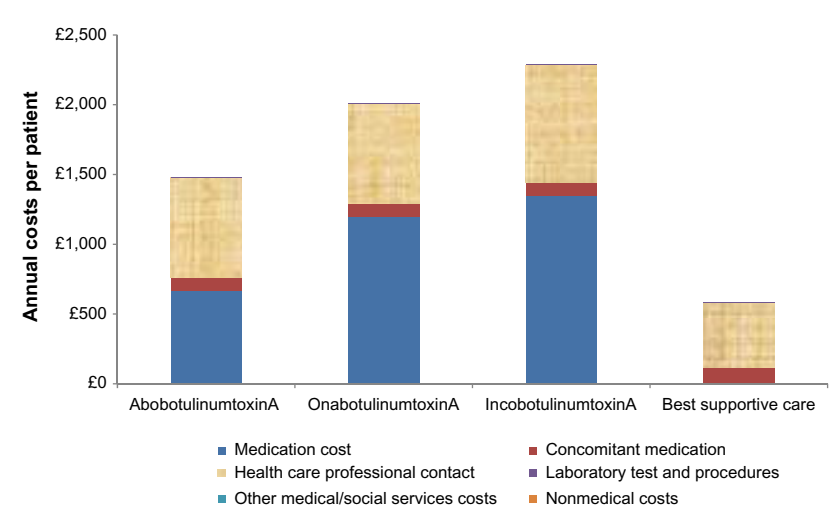

Figure I Cost of BoNT-A and best supportive care per patient per year by cost component.

Abbreviation: BoNT-A, botulinum neurotoxin A. 


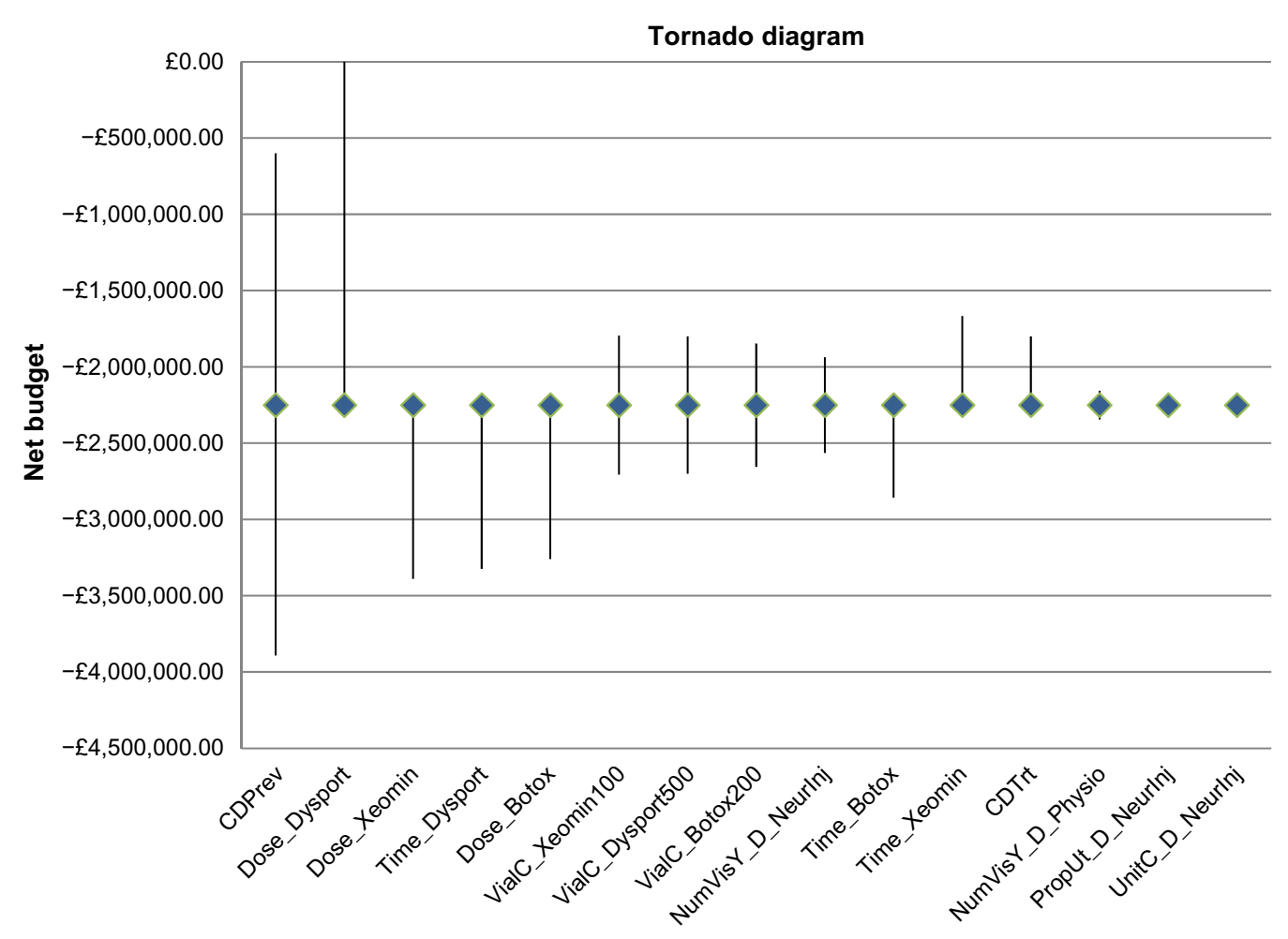

Figure 2 Tornado diagram of one-way sensitivity analysis showing the parameters that are most influential on net budget impact.

that although the latter of these costs is much lower for best supportive care compared to any of the BoNT-As, the use of concomitant medication was higher for patients treated with best supportive care.

The use of "real-world" exploratory data ${ }^{27-29}$ for the doses of abobotulinumtoxin $\mathrm{A},{ }^{27}$ onabotulinumtoxin $\mathrm{A},{ }^{28}$ and incobotulinumtoxin $\mathrm{A}^{29}$ showed broadly similar results to our primary analysis, reaffirming the net budgetary savings. The "real-world" analysis estimated accumulated savings of $£ 1,653,441$ as a result of an increased uptake of abobotulinumtoxinA, and the total costs per year of treating each patient with abobotulinumtoxin A, onabotulinumtoxinA, and incobotulinumtoxinA were $£ 1,596, £ 1,888$, and $£ 2,285$, respectively. This indicates that treating patients with $\mathrm{CD}$ with abobotulinumtoxinA could potentially save over $£ 680$ per patient per year. The major cost drivers were consistent with the findings in our primary analysis.

Our analysis is not without limitations. One major limitation we encountered while identifying model inputs for our analysis is related to the prevalence of $\mathrm{CD}$ in the UK. Previously published literature found the prevalence of CD to vary between $0.0057 \%$ and $0.037 \%$, corresponding to between some 3,600 and 24,000 patients with $\mathrm{CD}$ in the UK (Ipsen Biopharm Ltd, unpublished data, 2012). ${ }^{6,20}$ These figures are considerably below the estimates of the Dystonia
Society, which suggests that there could be up to 70,000 patients with CD in the UK. ${ }^{21}$ It should be noted though that the Dystonia Society estimates include patients with other diseases apart from CD, which is why this figure was not included in our analysis. Another limitation is the dosage of BoNT-A injections. In clinical practice, there is wide variation in the mean injection doses and the time to reinjection of these injections. The SPC dosage and reinjection interval suggestions for each of the BoNT-As were therefore used in our analysis, while the ranges for both dosages and reinjection intervals were based on assumptions from a clinical expert. In order to assess the robustness of the budgetary differences associated with the use of the SPC data, we performed a "real-world" exploratory budget impact analysis, where the data used were identified from previously published observational studies of treatment patterns for abobotulinumtoxinA, onabotulinumtoxin A, and incobotulinumtoxinA. Information on reinjection time was not available in previously published literature; thus, we maintained the original SPC time to reinjection suggestion for each of the BoNT-As. Results from this "real-world" scenario were broadly similar to those in the base case, indicating that the use of BoNT-As could lead to significant budgetary savings.

Our budget impact analysis did not specifically consider differences in efficacy or safety of the three 
BoNT-A preparations. Given the absence of head-to-head comparisons, any potential cost differences arising from dissimilar responses or adverse effects were hence assumed to be zero.

Finally, our approach was conservative in assuming that there was wastage - ie, physicians administering the injection would use the smallest possible combinations of available vial sizes and discard any remaining content of the vials after each session. Consequently, the budget estimates may have been underestimates that potentially indicate lower costs with the use of BoNT-A treatment.

\section{Conclusion}

While data on the epidemiology of CD is sparse in the UK, the cost burden associated with the management of patients with $\mathrm{CD}$ is high. The analysis found the potential for cost savings associated with greater use of abobotulinumtoxinA rather than other BoNT-A treatments, permitting more patients to stand to benefit from effective BoNT-A treatment with a fixed budget.

\section{Acknowledgments}

This study was funded by Ipsen Pharma. The abstract of this paper was presented at the 18th International Congress of Parkinson's Disease and Movement Disorders, 2014, as a poster presentation with interim findings. The poster's abstract was published in the "Poster Abstracts" in Movement Disorders Volume 29, June 2014 Abstract Supplement: http://www. mdsabstracts.com/abstract.asp?MeetingID=801\&id=112338. The actual paper, however, has never been published. No additional data are available.

\section{Author contributions}

$\mathrm{KD}$, JD, and SG reviewed all stages of the work, including model development, evaluation of selected data sources, and critical review of the results. TH reviewed the final model structure, data sources and results, and provided expert opinion for the model inputs that were unavailable from published sources. SB and SA gathered the data necessary for the model and performed model analyses. Additionally, SB performed the model programming, and SA wrote the manuscript. All authors critically reviewed the final version of the manuscript for its content and accuracy and agree that the conclusions presented are appropriately balanced. All authors contributed toward data analysis, drafting and revising the paper and agree to be accountable for all aspects of the work.

\section{Disclosure}

$\mathrm{SA}, \mathrm{SB}$, and $\mathrm{KD}$ are employees of Evidera Inc., which received consultancy fees to conduct the research from Ipsen Pharma. JD and SG are both full-time employees of Ipsen Pharma. TH has received consultancy fees from Ipsen Pharma. Ipsen Pharma did not have any influence on the interpretation of the data, as well as on the final conclusions drawn. The authors report no other conflicts of interest in this work.

\section{References}

1. Bloudek L, Stacy M, Schwartz M, Brin M, Papapetropoulos S. Cost of cervical dystonia in the United States [abstract]. Movement Disorders. 2012;27 Suppl 1:1005.

2. Coelho M, Valdas AF, Mestre T, Ferreira JJ. Pain and quality of life in the treatment of cervical dystonia. European Neurological Review. 2009;4(2):74-78.

3. Marras C, Van den Eeden SK, Fross RD, et al. Minimum incidence of primary cervical dystonia in a multiethnic health care population. Neurology. 2007;69(7):676-680.

4. Velickovic M, Benabou R, Brin MF. Cervical dystonia pathophysiology and treatment options. Drugs. 2001;61(13):1921-1943.

5. Steeves TD, Day L, Dykeman J, Jette N, Pringsheim T. The prevalence of primary dystonia: a systematic review and meta-analysis. Mov Disord. 2012;27(14):1789-1796.

6. Epidemiological Study of Dystonia in Europe (ESDE) Collaborative Group. A prevalence study of primary dystonia in eight European countries. J Neurol. 2000;247(10):787-792.

7. Albanese A, Asmus F, Berardelli A, et al; EFNS MDS-ES Task Force. Guidelines for the Diagnosis and Treatment of Primary (Idiopathic) Dystonia. EFNS MDS-ES Task Force. Available from http://www. movementdisorders.org/MDS-Files1/MDS-ES/guidelines_on_dystonia. pdf. Accessed December 14, 2012.

8. The National Institute for Health and Clinical Excellence (NICE). Selective Peripheral Denervation for Cervical Dystonia. London, UK: The National Institute for Health and Clinical Excellence; 2004.

9. Walker FO. Botulinum toxin therapy for cervical dystonia. Phys Med Rehabil Clin NAm. 2003;14(4):749-766, vi.

10. Jankovic J. Botulinum toxin therapy for cervical dystonia. Neurotox Res. 2006;9(2-3):145-148.

11. Burbaud P, Ducerf C, Cugy E, et al. Botulinum toxin treatment in neurological practice: how much does it really cost? A prospective cost-effectiveness study. J Neurol. 2011;258(9):1670-1675.

12. Hilker R, Schischniaschvili M, Ghaemi M, Jacobs A, Rudolf J. Health related quality of life is improved by botulinum neurotoxin type A in long term treated patients with focal dystonia. J Neurol Neurosurg Psychiatry. 2001;71(2):193-199.

13. Skogseid IM, Malt UF, Røislien J, Kerty E. Determinants and status of quality of life after long-term botulinum toxin therapy for cervical dystonia. Eur J Neurol. 2007;14(10):1129-1137.

14. Slawek J, Friedman A, Potulska A, et al. Factors affecting the healthrelated quality of life of patients with cervical dystonia and the impact of botulinum toxin type A injections. Funct Neurol. 2007;22(2): 95-100.

15. Skogseid IM, Røislien J, Claussen B, Kerty E. Long-term botulinum toxin treatment increases employment rate in patients with cervical dystonia. Mov Disord. 2005;20(12):1604-1609.

16. Molho ES, Agarwal N, Regan K, Higgins DS, Factor SA. Effect of cervical dystonia on employment: A retrospective analysis of the ability of treatment to restore premorbid employment status. Mov Disord. 2009;24(9):1384-1387. 
17. Brockmann K, Schweitzer K, Beck G, Wachter T. Comparison of different preparations of botulinumtoxin $\mathrm{A}$ in the treatment of cervical dystonia. Neurology Asia. 2012;17:115-119.

18. British National Formulary [webpage on the Internet]. Joint Formulary Committee. British National Formulary; 2012. Available from: https:// www.medicinescomplete.com/mc/bnf/current/. Accessed December 14, 2012.

19. Personal Social Services Research Unit [webpage on the Internet]. Unit costs of health and social care 2011: compiled by Lesley Curtis. Kent, UK: Personal Social Services Research Unit; 2011. Available from: http://www.pssru.ac.uk/project-pages/unit-costs/2011/index.php. Accessed December 14, 2012.

20. Erjanti H, Marttila R, Rinne U. The prevalence and incidence of cervical dystonia in south-western Finland. Mov Disord. 1996; 11(Suppl 1):A215.

21. The Dystonia Society [webpage on the Internet]. Cervical dystonia. London, UK: The Dystonia Society; 2014. Available from: http://www dystonia.org.uk/index.php/professional-research/types-of-dystonia/ cervical-dystonia. Accessed June 2, 2014.

22. MHRA. Dysport Powder for Solution for Injection and Botulinum Toxin Type A Powder for Solution for Injection (Clostridium botulinum Type A Toxin - Haemagglutinin Complex). PL 34926/0014 and 0015. Slough, UK: UKPAR; 2011. Available from: http:/www.mhra.gov.uk/home/ groups/par/documents/websiteresources/con108612.pdf. Accessed July 22, 2014.

23. MHRA. Botox (Botulinum Toxin Type A). PL 00426/0074-0110, PL 00426/0118-0030, PL 00426/0119-0012. Slough, UK: UKPAR; 2012 Available from: http:/www.mhra.gov.uk/home/groups/par/documents/ websiteresources/con208720.pdf. Accessed July 22, 2014.
24. MHRA. Xeomin 100 LD50 Units Powder for Solution for Injection. Slough, UK: UKPAR 2012. Available from: http://www.mhra.gov. uk/home/groups/spcpil/documents/spcpil/con1427432040685.pdf. Accessed July 22, 2014.

25. Han Y, Stevens A, Dashtipour K, Hauser R, Mari Z. A mixed treatment comparison (Mtc) to compare the efficacy of botulinum toxin type A treatments for cervical dystonia. Value Health. 2014;17(3):A57.

26. Albanese A, Abbruzzese G, Dressler D, et al. Practical guidance for $\mathrm{CD}$ management involving treatment of botulinum toxin: a consensus statement. J Neurol. Epub 2015 April 1.

27. Hubble J, Schwab J, Hubert C, Abbott CC. Dysport (botulinum toxin type A) in routine therapeutic usage: a telephone needs assessment survey of European physicians to evaluate current awareness and adherence to product labeling changes. Clin Neuropharmacol. 2013; 36(4):122-127.

28. Marchetti A, Magar R, Findley L, et al. Retrospective evaluation of the dose of Dysport and BOTOX in the management of cervical dystonia and blepharospasm: the REAL DOSE study. Mov Disord. 2005; 20(8):937-944.

29. Misra VP, Ehler E, Zakine B, Maisonobe P, Simonetta-Moreau M; INTEREST IN CD group. Factors influencing response to Botulinum toxin type $\mathrm{A}$ in patients with idiopathic cervical dystonia: results from an international observational study. BMJ Open. 2012;2(3). pii: e000881.
ClinicoEconomics and Outcomes Research

\section{Publish your work in this journal}

ClinicoEconomics \& Outcomes Research is an international, peerreviewed open-access journal focusing on Health Technology Assessment, Pharmacoeconomics and Outcomes Research in the areas of diagnosis, medical devices, and clinical, surgical and pharmacological intervention. The economic impact of health policy and health systems

\section{Dovepress}

organization also constitute important areas of coverage. The manuscript management system is completely online and includes a very quick and fair peer-review system, which is all easy to use. Visit http://www.dovepress.com/testimonials.php to read real quotes from published authors. 